\title{
Virumaa vanasõnad ja kõnekäänud ${ }^{1}$
}

\begin{abstract}
Anneli Baran
Teesid: Artiklis käsitletakse ühe Eestimaa piirkonna - Virumaa - rahvaluule lühivorme. Osutatakse omaaegsete kihelkondade tihedatele seostele rahvaluulelise materjali osas, mida iseloomustab arhailisus, murdelisus ja tugev regivärsi mõju. Piirkonna eripäraks on ka mõjud hõimlastelt, kes elasid kunagi nendel samadel aladel, ning naaberrahvastelt. Vanasõnade ja kõnekäändude seas torkab silma ainulaadsete väljendite rohkus, aga ka laialt tuntud eestikeelsete traditsiooniliste väljendite esmaesinemine. Rahvalike ütluste seas eristatakse nn naabrihuumorit ja kohanimedega pejoratiivseid ütlusi, tuues välja eelkõige paikkonnale iseloomulikku.
\end{abstract}

Märksõnad: fraseologism, kohanimed, murdekeel, naabripilked, regivärsivorm, vanasõnad

\section{Virumaa vanasõnadest - iseloomulikku}

Virumaad peetakse üheks Eesti olulisimaks folkloorialaks. Viru-, Harju- ja Järvamaa kokkupuuteala kihelkondadest on saadud kõige enam omaaegsete regilaulude kirjapanekuid. Vanasõnauurija Arvo Krikmann on tuvastanud, et ka selle piirkonna vanasõnavariantide hulk on üks suuremaid. Samuti kohtab Virumaa vanasõnades, iseäranis rannarahva omades, omaaegset regivärsivormi enam kui mujal. Siin on nii pudemeid üldtuntud regilauludest kui ka selliseid värsipaare, millel puudub seos rahvalauluga (Krikmann 1981: 40). Lisaks arhailisele vormile on kauemini säilinud vanapärane keelekasutus, kõnekeelest ammu kadunud arhailised keelendid, mille mõistmiseks vajame tänapäeval etnograafiaalaseid teadmisi. Tihedate naabrisuhete tõttu soomlaste ja venelastega kohtab Virumaa vanasõnade seas ka nendest keeltest laenatud ütlusi. Samuti on eripärane Alutaguse murdeala (Lüganuse, Jõhvi, Iisaku), kus kunagi elasid meie hõimurahvaste - vadjalaste ja isurite esindajad. See seik 
selgitab mõjutusi mitte üksnes murdekeelele, vaid ka rahvaloomingule. Just siit paikkonnast on kirja pandud ühiseid vanasõnu vadjalastega.

Tähelepanuväärne on seegi, et on piirkondi, nt Iisaku kihelkond, mille eri osad kuuluvad keeleliselt erinevatesse murderühmadesse. Nii on rikkalikult vanasõnu ja kõnekäände andnud Tudulinna ümbrus hoopiski idamurde koosseisus, samal ajal kui ülejäänud osa Iisakust on jagatud Alutaguse murde (ehk kirderannikumurde ühe murderühma) ja keskmurde vahel.

Selline murdealade sujuvate piiride olemasolu ongi põhjuseks, miks võib mingi ühe kihelkonna vanasõnade ja muude ütlustegi koosseis olla üpris eriilmeline.

Puhtalt ühe kindla kihelkonnaga piirduvate vanasõnade kõrval on rohkem pigem selliseid, mis ulatuvad naaberkihelkondadesse, olgu siis sama maakonna omad või siis koguni sellest väljapoole jäävad. Seesuguse levimise põhjuseid tuleb näha nii omaaegses asustusajaloos kui suhtluses, läbikäimises naabrite vahel.

"Eesti vanasõnade" akadeemilise väljaande (EV) andmetel ${ }^{2}$ on Virumaa erinevaid vanasõnatüüpe kõige enam kirja saanud Lüganuselt - 943, järgnevad Haljala 929, Rakvere 684, Jõhvi 653, Väike-Maarja 587, Viru-Nigula 574, Iisaku 392, Vaivara 362 (lisaks Narva 139), Kadrina 320, Simuna 298, Viru-Jaagupi 185 tüübiga. Väljaandes esitatud vanasõnade üleskirjutused kuuluvad peaasjalikult ajavahemikku alates 1888 . aastast ja lõpetades 1960 . aastatega. ${ }^{3}$ Rahvaluule suurkogumise algusajal on vanasõnu ja kõnekäände tallele pannud ja arhiivi läkitanud järgmised kirjasaatjad: Juhan Elken (VMr, VNg), Aleksander ja Friedrich Feldbach (Vai), Aleksander Heraklides (Rak), Alfred Konstantin Kivi (Kad), Kaarel Kleinmann (Kad), Hans Krickmann (VNg), Johannes Leetberg (Hlj), Leena Lepp-Viikmann (Pruul) (Hlj), Juhan Lilienbach (Rak), Karl Voldemar Lurich (VMr), Hermann Länts (Hlj), Heinrich Masing (Vai), Carl Mastberg (VMr), Nigolas Otto (Jõh), Paulus Paurmann (Jõh), Karl Danel Pruhl (Hlj), Julius Aleksander Rehberg/Reepärg (Hlj), Marsell Ross (VMr), Johannes Sirdnak (Nrv), Johannes Sõster (Kad), Dietrich Timotheus (Iis, Jõh).

Hilisemast perioodist pärinevad mahukamad saadetised jäävad üksikute eranditega peaasjalikult 20. sajandi teise poolde: Marta Blum-Koppel (Iis), Helmut Joonuks (Sim), Hilda Jõulmaa (Iis, Jõh), Arvo Krikmann (Sim), August Krikmann (VNg, Rak), Aino Källo (Lüg), Edur Maasik (Iis), Endel Mets (Jõh), Madis Oviir (VJg), Linda Palu (Hlj, Rak, Sim), Mihkel Priimets (VMr), Mall Proodel (Hiiemäe) (Iis, VMr), Oskar Surva (Iis), Johannes Valdur (Kad).

Teistest piirkondadest esileküündivamat temaatikat Virumaa vanasõnades ei kohta. Peamised teemad on vanasõnadele üldiselt omased: loodus ja ilmastik, kalender, põlluharimine, majapidamine, tervis, perekond ja kodu. ${ }^{4}$ Samuti on esindatud vanasõnad inimsuhete, oma ja võõra, sotsiaalse ebavõrdsuse, oman- 
disuhete, headuse ja kurjuse, töötegemise ja kokkuhoiu, nooruse ja vanaduse, elu ja surma kohta. Ent nagu on märkinud Arvo Krikmann (1981: 38), on nn etnograafilise temaatika (kalender, ilmastik, põlluharimine, kalastamine, argielu, ametid jms) osakaal rannarahva vanasõnarepertuaaris suurem võrreldes teiste Eesti aladelt kirjapanduga.

Võimalik on välja tuua kõigi Virumaa kihelkondade ainulised vanasõnatüübid, st sellised, mis esinevad Eesti Rahvaluule Arhiivi andmetel üksnes ühes kihelkonnas. Iseloomulik on, et seesuguste tekstide osakaal on suhteliselt väike. Reeglina tunti üht ja sama vanasõna ka väljaspool kihelkonda. Nii ilmnebki, et Haljala vanasõnu kohtab ka Kuusalus ja Kadrinas, Jõhvi omi Iisakus ja Lüganusel, Lüganuse omi Haljalas ja Rakveres, Rakvere omi Viru-Nigulas jne. Samuti on iseloomulik, et mingi vanasõna tuntus ühendas Virumaa kihelkondi hoopis Põhja-Tartumaa (Torma, Laiuse, Palamuse, Kodavere), Harjumaa (Kuusalu, Jõelähtme, Jüri) või Järvamaaga (Ambla, Järva-Jaani, Koeru). Rannaeestlaste traditsiooni esindavad ilmekalt Haljala, Kadrina, Lüganuse, Viru-Nigula ja Jõhvi vanasõnad, siin esineb rohkelt regivärsile omast algriimi ja parallelismi. Kuigi enamasti on tegemist regilauludest iseseisvunud värsiridadega, ei ole sugugi kõik seesugused tekstid alati otseses seoses mingi kindla rahvalauluga. Leidub nt üksnes Haljalas või Kadrinas kirja pandud vanasõnu, siiski on suur osa neist regivärsivormilistest vanasõnadest ühised Kuusalu kihelkonnaga. Nii on Krikmann (1981: 5) osutanud Virumaa teatud kihelkondade vahelistele tihedatele omavahelistele seostele, tehes seda just nn puht-lahemaaliste (Kuusalu, Haljala, Kadrina) vanasõnade näitel.

Kirderanniku levikutüübi kõrval eristub kirde-eestiline tüüp, mis seob Virumaa mereäärsete kihelkondade ehk Ranna-Eesti ala traditsiooni sise-Virumaa kaudu Peipsi-äärse piirkonnaga (vt siirdealadest Pajusalu jt 2002: 91-94). Krikmann (1981: 12) on Virumaa mõnede sisemaiste kihelkondade (Simuna, Viru-Jaagupi) puhul aga märkinud vanasõnalise ainese vähest kogumist, mistõttu on seesuguse levikusuuna konstrueerimine pigem oletuslik.

Järgnevas on toodud näiteid vanasõnatüüpidest Virumaa kihelkondades EV põhjal. Esmalt kihelkondade kaupa ainuliste vanasõnade loend.

\section{Haljala kihelkond (Hlj)}

Ega töö konn ole, et eest ära hüppab.

Hildarusku hüvä päivä, aamurusku päivä paska.

Hobu kaup on õuessa, neidu kaupa kamberissa.

Hommiku kukega, õhtu koeraga.

Kuhu iga töömees oma järelejäänud tükid paneb: kingsepp saapaapsatisse, rätsep kuuekrae sisse, müürsepp müüri vahele. 
Kui on läind rumm, siis mingu ka kodarad.

Kuusk kuulutab, lepp laulatab, pajupõõsas paneb paari.

Küll vend venna tunneb.

Mida rikkam, seda tigedam.

Parem silk-leib kohu sees, kui kuldtukat pihu sees.

Pere leivad piened leivad, talu leivad targad leivad, nied tahvad suurta sõtkujaida.

Põld paneb puhkamaie, ie paneb hingamaie.

Raha on ümmarguine.

Suvel oled suureline, küll talvel tagasi annad.

Süga sina täna mind, mina süga homme sind.

Vareksel on vagu taga ja harakal on hagu taga.

Võeras lehmake, oma kelluke.

Võtja käsi piab pikem olema.

Ära vana koera torgi.

\section{Jõhvi kihelkond (Jõh)}

Jo laastust tunneta meistri.

Kis varga järelt varastab, küll sie naerab.

Kui ei õle piad õtsas, anna aga jalgudele valu.

Kui enne paastumaarjapäeva külm on, siis on pärast soe; on enne soe, siis on pärast külm.

Kui karu otsib vara pesa, tuleb vara külm.

Kui ülestõusmesepühal nii soe on, et võib kuueväel käia, siis piab nelipühi nii külm olema, et käi kasukaga.

Küll igaüks oma randa roogib.

Muik muie rahva ies, kena kerikutiel, kodo kulpi kusevad, soolavakka soravad.

Naist sõnast, lutsu sabast.

Olgu õlgine ehk aganane, kui aga oma on.

Parem ikke uues kuues kui vanas kasukas.

Silk-leib ja raavivesi - nied on saarlase toit.

Zissid-Zimmid sõja võitsid, Stuudebakid muidu sõitsid.

Tanguputru on ülä aia hüppädä.

Töö ei ole hunt, et metsa jookseb.

Tütarlapse suul olgu alati porstuba ees.

Õige pääle kadeda hammas ei hakka. 


\section{Iisaku kihelkond (Iis)}

Kolm on koosolek.

Kui valusat ei ole, siis pole ka ilusat.

Küll luts loeb, latikas laalab.

Lehmasõnnik on jumalasõnast vägevam.

Lutsu maksad ja maualused, kiissel ja kartulipudru - vat sie on kõige parem roog.

Mees on nagu kuusepakk, vahetevahel praksub; naine on nagu haavahalg, alati sisiseb.

Mitu päeva pääle jaanipäeva kägu kukkub, nii mitu nädalat on pääle mihklipäeva sooja.

Puud tuleb lautida nii, et värblane läbi lennab, aga harakas kinni jääb. Silkusöönd mehed olla tugevad.

Surmast ei ole koledamat ja Siberist ei ole pikemat teed.

Tervist apteegist on ju raske tuua: paljukese sealt saab.

Tropis peab ikka tola olema.

Valel on saba taga.

Võõras rand, võõras kala.

Õlu peab nii rammus olema, et kass võib poegadega peal istuda.

Üks on luadud luulijast, teine on luadud laalijast, kolmas musta mulla püerijast.

\section{Kadrina kihelkond (Kad)}

Ainult need saavad mehele, kes on osavad ning sõlmivad kuuseokka sõlme. Enne toomapääva võib ôlut aganatestki teha, piale toomapääva ei saa viljastki.

Head sõbrad ikka oma nahka nülivad.

Inimene on surmani koolilaps.

Keed ei sünni keeduksesse.

Kes palju näeb, see palju teab, aga hea, kes vähe näeb ja siiski teab.

Kui punane kukk laulab katusel, siis on kõik lõppend.

Mulk on kõrge, mulk on rumal.

Olgu ikka üks lootsiku tü̈̈rimees, teised seesistujad.

Pikad juuksed, pikk aru; lühikesed juuksed, lühike aru. 


\section{Lüganuse kihelkond (Lüg)}

Ega kana iga kõhtagi ei muni, kuhu kükitab.

Huoletus ja laiskus on õessed.

Juodikku Jumal juhatab.

Kana kaagutab pärast, naine enne.

Keeled suus - tied lahti.

Kuda jalg, ninda saabas.

Kui naine paneb suure varba suhu ja jala kaela peale, siis naine on viel naine.

Kui puudub majas tüö ja huol, siis kaub lauvalt leib ja suol.

Kui saad üle luvva, sis üle luvva varre $k a$.

Laubane päiv on ühe otsaga.

Lesk naine ja kaartulid on saarnased, sest neie mugulad on mulla all.

Mehe sugulased on kui jänesse tagumine jalg.

Naine on viel naine, kui kusi lume sulatab.

Nuorelt rabad, vanalt magad.

Parem oma soolleib kui võera võileib.

Surm ei küsi, kas sa noor ehk vana.

Tänä vana mattab, homme uuve võttab.

Vanalt kondid vastavad.

Virk ärkab, siis torkab, aga laisk jääb lamama.

Võta sie naisest, kie luuavarre maast üles tõstab.

Väsind inimene magab ka puuhalu pääl.

Õigus on kirju härjä perses.

Ära vali pali: kie pali valib, sie palja saab.

\section{Rakvere kihelkond (Rak)}

Anna viimane käest välja, viimaks jää ise vesilusikale.

Ega kõik tiha sünni, mis kässässe, käskida võib ka: istu persetpidi tulde.

Ega sie ise nii hia ole, kes teist naerab.

Ei surm küsi kellegi kääst luba.

Ennemb en saa henge tagasi, kui kaks kätt rindul.

Hia asi saab ennemast otsa.

Härja suuruse au veeb kass sava otsas ära.

Jägajal puuduvad näpud põhja.

Kas hane selga loputa ehk lollil tarkust ópeta. 
Kes kõige laisem lubama, on tihti tulisem tegema.

Kes saab, see salvab.

Koera ase on laua all.

Kui mere peal häda, siis maa peal aitajaid küll.

Kui oled mees, siis pea mehe aru.

Kust rikas raha saab.

Mis sa sest viel taga lükkad, kes kukkumas on.

Pea harv, jalg kerge.

Pea pahane unestab, jalad vaesed vastagu.

Teist oskab igaüks õpetada.

Tühi jutt lagub jaani jääle ära.

Vaene toidab rikast.

Õpitud ammetit on raske maha jätta.

Ühekorra piab ikke surema.

\section{Simuna kihelkond (Sim)}

Ega koer tuult haugu.

Ilma koppel on suur ja seal sees on iga karva vasikaid.

Kes valetab, see kannatab.

Kes vasikas õhtul, see vasikas hommikul.

Kes väikselt alustab, lõpetab suureste.

Kiida lolli, loll jookseb nahast välja.

Kui on mees rahul, siis on ka Jumal rahul.

Kui vana karu läheb pesast välja, siis pojad jäävadki sinna käppa imema. Kurat on valeliku isa.

Kõik ep ole nii suured rikkad, kuda kiidetakse, kõik ep ole nii suured vaesed, kui laidetakse.

Põllumees on saatuse ori.

Sõber on parem kui kõige ligem ligemene.

Vaene on rikka selgroog.

Ära räägi rohkem, kui võid teisele suu sisse öelda.

\section{Vaivara kihelkond (Vai)}

Ennemuina öölnud härg: "Täis mees, täis mõet: kubu õlgi ja toover vett." Enne toapoiss, pärast seapoiss, aga enne seapoiss, pärast toapoiss.

Hommikune aeg - kuldne aeg. 
Kahjust on kägo külasse, tülist on tütar talosse.

Kes tahab palju saada, peab palju kannatama.

Koer haugub kuni hammustab.

Kui mihklipäeval tuul pöörab, siis viljahinnad ka pööravad.

Lööb saadan sarved seina, võta siis seinast välja.

Matiga võetakse, vakaga saadakse.

Naised ütlevad, et rohkem pole miest vaja kui siis, kui näeb madu-ussi ja kui müristab.

On ööd uneta, siis tööd eluta.

Pärast riidu ei ole tarvis rusikad näidata.

Sappi on saivarilgi.

Tüö sunnib tegijat.

Valelikul on seitse reedet nädalas.

Veikesed allikad teevad suured jõed.

Äga küla külla ei anna.

Üks teeb, aga üheksa saab.

\section{Viru-Nigula kihelkond (VNg)}

Elu hea, kui teised ei tea.

Ennem saab hundist hobune kui karust koduloom.

Kergem on koguda kui kokku hoida.

Kui kadrinapääva sula, siis olla andreksepääval jälle külma.

Küla kiidab, mõis laidab, mõis kiidab, vald laidab.

Lapsed lapsida tegevad vanemile vastuksista.

Oled ise sikk, siis võta ka kitse omale naiseks.

Pee on peksu karjamaa.

Puu paindub, aga mees ei taibu.

Sõpru saad, kui sinul nendele anda on, vaenlasi, kui neilt midagi tahta tahad.

Sü̈̈ keitjal, sü̈̈ sööjal.

Töölt leitakse, tegijaks kiidetakse.

Tütarlapsed tühjad asjad, pojad need on mehed.

Vanapoiss maksab vaka süsi, vanatüdruk maksab tünder nisu.

Vastavetta on raske uju.

Õde ounaoksakene, vend on vestuvarrekene.

Õigus ei kõigu. 


\section{Viru-Jaagupi kihelkond (VJg)}

Este hirmus, pärast armas.

Küll siis surm sü̈̈d leiab, kui taud tappa tahab.

See on küll teinud, kes haudas on.

Sel inimesel on hea elada, kes häbi ega au ei karda.

Viksid viia viisi tõttu, kõrgid kena kõnni tõttu, töö tõttu tütarlapsed.

\section{Väike-Maarja kihelkond (VMr)}

Anna kurjale tilka verd, pärast võtab kuri hinge.

Ega kroonu leib ei lõppe.

Ega vihmavesi katuselle jää.

Ei vesi ega tuli ühte hakka.

Harvast häid nähakse.

Iga suksutaja ei ole päitsete pähepanija.

Inimene on ise oma jumal ja ise oma kurat.

Kadedus on kuradi ema.

Kes kalu kätega püüab.

Kes tööd teeb ja vaeva armastab, seda aitab Jumal.

Kui voodid ei ole, aitab ka muru.

Oma teenitud leib on magusam võõrast.

Parem heaga herneleem kui pahaga pannkoogid.

Peremehe "läheme" on enam kui peremehe "minge".

Sitikal on siledad tiivad, tartlasel targad sõnad.

Tantsi, tantsi täna, küll hommen ajad pilli.

Õigust kardetakse rohkem kui tuld.

Üks väljal ei ole mitte sõjavägi.

Järgmisena toon välja vanasõnad, mis esinevad ainult kahes Virumaa kihelkonnas. Antud näidete puhul on nendeks paarilisteks teistest sagedamini JõhviVaivara ning Haljala-Rakvere.

Ega vesi verd anna.

Hea, kes hästi räägib, veel parem, kes vait seisab.

Hobu jookseb, kuni köie mõedab.

Isa pussik saab pojale, ema helmed tütterile.

Joobnu jutt ehk lapse laul.

Ka pime hobune leiab oma teed koju poole. 
Kahjust on kägo külasse, tülist on tütar talusse.

Kel raha, sel sõbrad.

Kerge on haigeks jääda, katsu tervest saada.

Kits ei ela kiitusest ega lammas laitusest.

Kuld kuolitab ja raha rihib.

Küll meri mihe tegeb.

Loe luid ja arva hambaid, ära loe teise loomi.

Maja rahu tuleb maja perenaisest.

Mingu kas või naine kaevu, aga piip peab põlema pandama.

Mis viga nielata, kui teine puruks närib.

Parem tuasittur kui kõrtsilakkur.

Puhtale on kõik puhas.

Raha sigitab vargaid.

Rebase saba paistab välja.

Seda kuuske kummardad, kelle all sa oled.

Sugulane suurem vaendlane.

Sulle lauad, mulle rauad.

Südamel ei ole mitte akant, kust sisse vaata.

Taga jõulut talv tuleb.

Tarkusest ei lähe kiegi lõhki.

Õnnetu tieb kõik ôhtad, vilets kõik videvikud.

Ainuliste vanasõnade ja Virumaa eri paikades levinud vanasõnade kõrval eritlen omaette rühmana vanasõnu, mis esinevad ühes või mitmes Virumaa kihelkonnas ja võivad ette tulla ka naabermaakonnas (Harjumaa, Põhja-Tartumaa, Järvamaa). Nagu on välja toonud Anne Hussar (2013: 103) Ida-Virumaa vanasõnade juures, võib näiteks üks ja sama tekst lisaks ühele Ida-Virumaa kihelkonnale (Vai, Jõh, Iis, Lüg, VNg, VJg) esineda veel Haljalas ja/või Kuusalus.

Ega vesi verd anna.

Hea, kes hästi räägib, veel parem, kes vait seisab.

Hommikune aeg - kuldne aeg.

Idast tuleb hä̈ ilm, idast tuleb paha ilm, idast tuleb maailma ots.

Ka pime hobune leiab oma teed koju poole.

Kergem on koguda kui kokku hoida.

Kes kõige laisem lubama, on tihti tulisem tegema.

Kits ei ela kiitusest ega lammas laitusest.

Kui saad üle luvva, sis üle luvva varre $k a$.

Kuida maa, nõnda maner.

Kuda mees, nõnda mekud. 
Kuld kuolitab ja raha rihib.

Loe luid ja arva hambaid, ära loe teise loomi.

Maja rahu tuleb maja perenaisest.

Mis viga nielata, kui teine puruks närib.

Naine on siis viel naine, kui või suus sulab.

Parem tuasittur kui kõrtsilakkur.

Pea harv, jalg kerge.

Raha sigitab vargaid.

Seda kuuske kummardad, kelle all sa oled.

Sugulane suurem vaendlane.

Sulle lauad, mulle rauad.

Söö ikka kala ja pala, kui peremees ei näe, siis veel.

Südamel ei ole mitte akant, kust sisse vaata.

Taga jõulu talvet küll, taga jõulu päävad pikad.

Tarkusest ei lähe kiegi lõhki.

Õnnetu tieb kõik õhtad, vilets kõik videvikud.

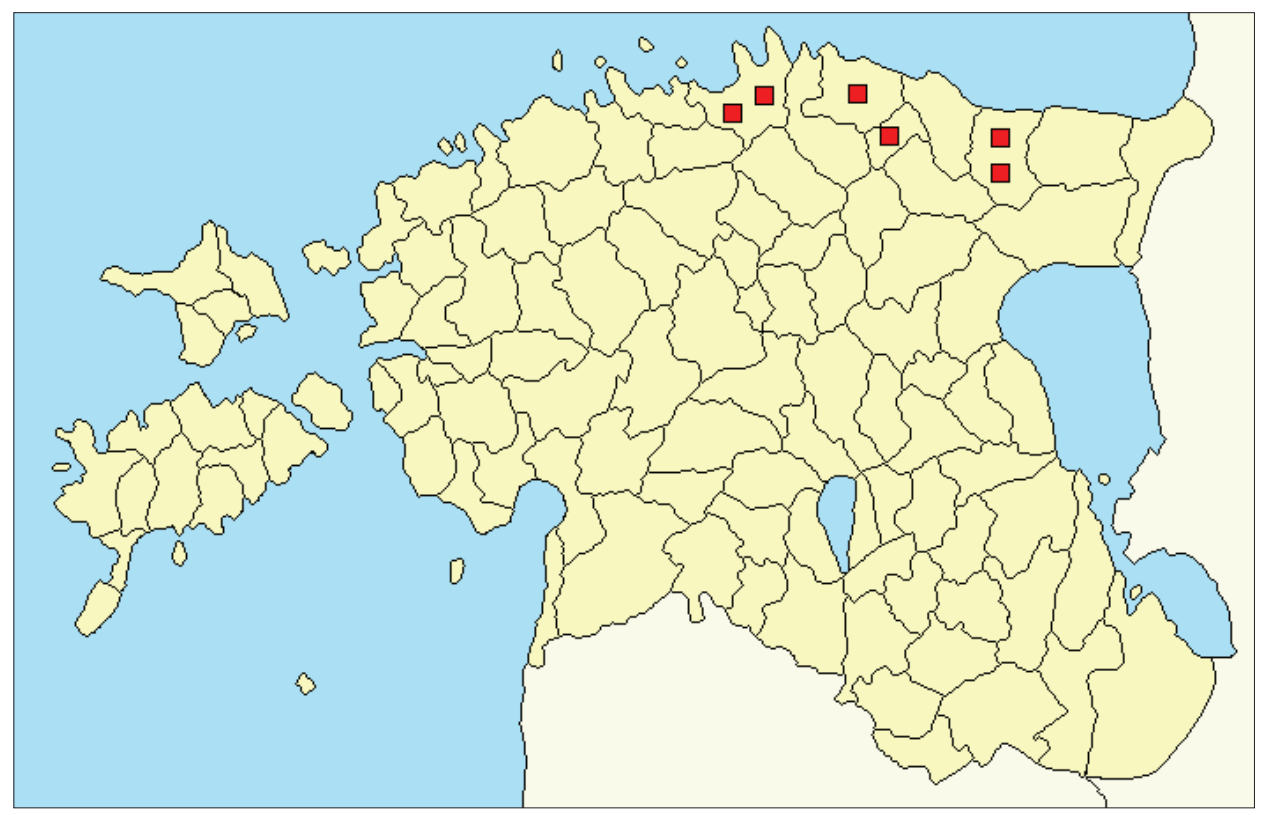

Joonis 1. EV 11267 Söö ikka kala ja pala, kui peremees ei näe, siis veel. 


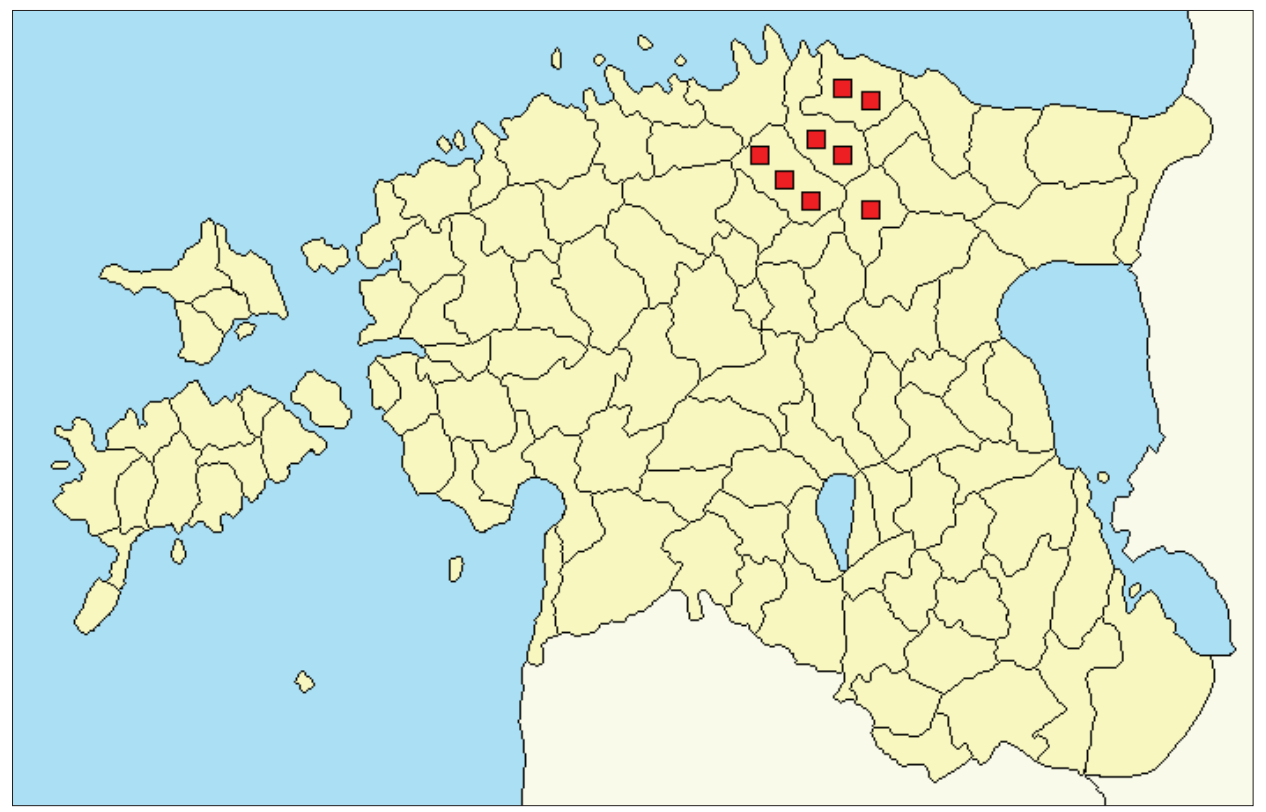

Joonis 2. EV 6511 Kuda mees, nõnda mekud.

Võib leida väga arhailisi tekste, mis osutavad kunagistele geneetilistele või laenulistele seostele läänemeresoome ainesega. Virumaa ühest piirkonnast Alutaguselt (määratlus "vadjapärane kirderajoon") on kirja pandud niisuguseid vanasõnu, mis on puhtalt vadja päritolu (Mälk 1976):

Kui eläme, siis helmed saame; kui sureme, siis kalmud saame.

Küla annab külma nõu, rahvas raudase südame.

Küla tuleb, küll saab; talu tuleb, taas saab.

Samuti leiab Virumaalt vanasõnu, mis on kas soome või vene päritolu (vt Hussar 2013). On kindlaks tehtud ka seesuguseid tekste, mis on ühised nii eestlastele (seejuures esinemus peaasjalikult Virumaal), soomlastele, vadjalastele kui ka venelastele. Siinkohal üksnes mõned näited, toetudes Vaina Mälgu uurimistööle (1976).

Aeg parandab haavad, aga jätab armid.

Kes haraka pesa ilmutab kui ise.

Igalühel ikke oma kallis.

Kolm on iga asjale hea. 
Kuera ei ole, haugu ise.

Igal maal ise viis, igas kohas ise kombed.

Ega puu ühelt puolt lange.

\section{Kõnekäänud ja muu fraseoloogiline keeleaines Virumaal}

Kõnekäänd ehk rahvapärane fraseologism on kujundlik iseloomustus mingi üksikjuhu kohta. Erinevalt vanasõnast ei ole kõnekäänuline ütlus lausekujuline, vaid osa lausest. Piirjuhtudel võib kõnekäänd olla küll ka süntaktiliselt lõpetatud lause, ent siiski mitteüldistav.

Virumaa vanimad rahvapäraste fraseoloogiliste väljendite üleskirjutused pärinevad sarnaselt vanasõnadele rahvaluule suurkogumise algusest - aastast 1888. Sel aastal esitas Jakob Hurt oma üleskutse "Paar palvid ...", pannes aluse eesti rahvaluule süsteemsele kogumisele. Virumaalt kirja pandud varaseimad tekstid on ühtlasi nii mõnegi Eestis laialt tuntud väljendi esmasteks kirjapanekuteks (dateeringuks 1888) ${ }^{5}$ :

Aiateivas on su abi ja toeteivas on su tugi! (Kad)

Kaks täkku libeda kõrtsi ees. [Tatine nina.] (Jõh)

Kasvas küll habe, aga ei kasvanud mõistus. (VNg)

Olgu tema ruun ehk mära, maksa aga kaerad ära! (Hlj)

Käed kullased, suu sitane. [Varanduse kohta.] (Vai)

Nüüd on talve selg pooleks. (Rak)

Erandina torkab silma Viru-Nigula khk, kust varaseimad kõnekäändude kirjapanekud pärinevad juba aastast 1878-1879 (Eesti Kirjameeste Seltsi rahvaluulekogus). Kõigi nende üleskirjutuste taga on üks isik - Hans Krickmann. EKFA andmetel on ka need tekstid tuntud väljendite esmakordsed fikseeringud.

Kõht täis nagu rikka mehe ait.

Kui ei usu, siis anna uruaugule musu.

Laps nagu surma suutäis. [Lahja ja väikene.]

Roots ruol, ei vana venelane teagi. [Kui lapsed söövad.]

Tule koju, meeleke - kust tuleb, kui ei olegi.

Tõsi kui tõrre põhjas vesi.

Kõnekäändude üleskirjutuste koguarvult tõusevad teistest kihelkondadest märkimisväärselt esile kolm kihelkonda: Lüganuse, Iisaku ja Jõhvi. Ühtekokku on 
neist kirja pandud ligi kümme tuhat fraseoloogilist ütlust. Sama palju tekste on Virumaa ülejäänud kihelkondade peale kokku.

Sarnaselt vanasõnadega leidub fraseologismide seas väljendeid, mille päritolu piirdubki üksnes Virumaaga, ent enam kohtab siiski niisuguseid, mis on nii Virumaal kui naabermaakondade kihelkondades (sagedamini Kuusalu, Ambla, Koeru, Laiuse).

Puht-virumaalistena kirja pandud väljendite vormilise külje kohta võib nentida, et sarnaselt mõnede kihelkondade vanasõnadele kohtab siingi sagedasti regivärsile omast algriimi. Kõnekäänud, iseäranis vanemad, ongi tihtipeale seotud vanasõnadega - ühelt poolt nn koostisosana vanasõna sees, teisalt kõnekäänulise variandina (Krikmann 1997: 54-55). Ilmekas fraseoloogiline väljend vesilusikal olema/elama, vesilusikale jääma 'vaesuses olema, puudust kannatama' on kirja pandud üksnes Virumaalt. Samuti nagu ka vanasõna Anna viimane käest välja, viimaks jää ise vesilusikale!

Erinevalt vanasõnades tooniandvast tõsisest õpetusvaimust valitseb rahvapärastes väljendites peaasjalikult huumor - enamasti tögamise, pilkamise vmt kujul. Taolist rahvapärast humoorikat sõnaseadet kohtab nii võrdluste, liialdavate ütlemiste, teretamiste-tänamiste, retooriliste hüüatuste kui muude ütluste näol.

\section{Võrdlused}

kui kiurumunetaja [Väikesekasvuline, kõhna naise kohta.] (Lüg)

kõhn nagu küpse silgu silmade vahe (Hlj, Sim, VMr)

kõht täis kui kõrvekitsel (Nrv, VJg)

libe nagu vene seen (VMr)

mure nagu Rähni Maie munaruog (Iis, Jõh)

lüedi käppaga pähä nagu jänese pojale (Iis)

nagu mustlased jagavad Sirtsu soos kopsu [Kui mõne asja pärast jagelemist tuleb.] (Sim, VMr)

punetab näost kui rootsi koidik (Lüg)

\section{Hüperboolsed väljendid}

Ah, tema tüö või tegemine, sie on nisike, et küla koeradki naeravad. (Iis, Jõh)

Ei sie inimene seisa sõelas ega sarjas. ( $\mathrm{Hlj}$, Iis)

Jalad sel ninda kõverad, et põrsast pü̈̈da ei saa, põrsas juokseb jalgade vahelt läbi. (Jõh, Iis) 
Kuuleb, kui rohi kasvab. (Kad)

Küll siis hakkab ujuma, kui vesi perse puutub. (Iis, Jõh, Kad, Lüg, VNg)

Müts ei jõudnud varnas sõisama jä̈̈da. [Üeldi lühikäse puhkuse ja üö kohta suvel.] (Jõh)

Omal nokib kukk tagaõtsast tangu. [Kui keegi väga noor on ja tähtis.] (Lüg, Rak, Sim)

Suur püha, et rohigi ei kasva. (Kad)

Tie talle nisuke paldruk, et õite aitab. [Peksaandmise kohta.] (Sim)

Vaata kui virutan, nii et multsed kapsad lendavad! (Sim, VJg)

Ega sind ometegi hobuse naha sisse maeta. [Sellele, kes ülearu ennast hoiab.] (Hlj, Iis)

Ega ta ääri ei nuta [Kui on midagi juba parasjagu, aga ikka veel pisut juurde lisatakse.] (Hlj, Iis, Kad)

Karu tuli mul vastu ja mina ei saand muidu, kui kaks korda vaatasin talle näkku - nii suur nägu oli sel karul. (Rak)

\section{Teretamised-tänamised}

Aitäh tulemast, meie saime palju paremast ja suure tüki suuremast, kui tuleb homme, siis tule tagasi! ( $\mathrm{Hlj}$, Iis)

“Tere tömplik-tämplik!” - “Saab pesto, pliegitu, sile jumalime!” [Tervitus kangakudujale ja vastus kudujalt.] (Lüg)

\section{Retoorilised hüüatused ja küsimused, tõrjevormelid}

Mine Sirtsu sohu oma jutuga! (Iis, Lüg)

Mis sa nohised, kas on silgud otsas? (Iis, Kad)

Oh sa poiss ja puud ja laevad! (Kad)

Oh taevas, küll sa oled kondine! - Sa ei tea, kui magus liha on kontide vahel. (Lüg)

Pea oma alumine mokk kinni, ülemine seisab isegi! (Sim)

\section{Vellerismid}

“Kahi on kahi," nagu Lahtri Mahta ütles, kui muna põlle all katki läks. (Lüg)

Mustlane peeretab jõkke, joob: "Parem kui paljas vesi.” (Hlj) 


\section{Muud rahvapärased fraseoloogilised ütlused}

Iga niksu peale naks. (VMr)

Ike muie muga ja teiste taga. [Kui keegi teiste tagajärele kõik ära teeb.] ( $\mathrm{Hlj}, \mathrm{Rkv}$ )

Iretale ilma pika, Maretale maani pika, Piretale piriparaja Iretale ilma pika, Maretale maani pika, Tatsharakale taas paras. $(\mathrm{Hlj})$

Kala ja pala, silk ja suutäis. [Suure sööja kohta.] (Hlj)

Koer kolgib metsavilki. [Öeldakse, kui koer metsa poole haugub.] (VJg)

Kui on pühad, olgu õieti - too lauale mõlemad silgud! (Hlj, Kad, Rak, Sim)

Kus käbü, kus kalsi, kalakudu rannas. [Öeldakse siis, kui ei ole püügiriistad õigel ajal korda seatud.] (Hlj)

Küll on naljakas, kui laps on lollakas. (VJg)

Suu kui sutermundukene, silmad kui sibulikesed, kõrvad kui kukelulliksesed. (Jõh)

Vanade üleskirjutuste seast leiab loomulikult ka väljendeid, mis on juba oma keelekasutuselt puht-virumaalised. Need sisaldavad just selle piirkonna murretele iseloomulikku, olgu selleks siis soome või idapoolsete sugulaskeelte või läbinaabri vene keele mõjud. Nii esindavad Haljala, Viru-Nigula, Kadrina kirderannikumurde alale jäävat soomemõjulist rannamurret, kus algriim võimendub tänu häälikulisele omapärale, milleks on tugev vokaalharmoonia ning õ-hääliku puudumine. Alutaguse siirdemurret esindavad Lüganuse, Jõhvi, Iisaku, kus aga vastupidiselt valitseb õ-hääliku ületarvitus ja vene laensõnade rohkus (Ida-Virumaalt kokku 600 vene laenu, sh 100 Iisaku kakskeelselt alalt (Must 2000: 581)):

Jusku kuera õksendus [Korratu töö kohta.]

Oh sa kuradi semplakas! [Sõimusõna.]

Oled üks kapustapää! [Ei saa menestki aru.]

Pealt on ta nii peen, et oi, oi, oi, aga küll ta alt on hirmus prostoi. [Edev naisterahvas.]

Prostoi pütt ja piened kõrvad. [Öeldi vaese kohta, kes sakste moodi käed puusale pani.]

Sa söödad omi setverikust, aga mina tõstan toobiga!

\section{Paikkondlikust huumorist naabripilgete näitel}

Nii nagu teistegi rahvaste folklooris, leiab ka Eesti omast naabrihuumorit. Omal ajal olid taoliste osatamiste märklauaks hõimlased või naaberkihelkon- 
dade elanikud (Remmel 2003). Peaaegu igast Eestimaa piirkonnast võib leida iseloomulikku, just omakandi naabrussuhete kajastust. Nii tuleb mereäärsetelt aladelt kirja pandud rahvaluuletekstides ette vastandust: rannamees ja maamees. Vanasõnade poole pealt leiab juba väga vanadest käsikirjadest (A. ThorHelle, A. W. Hupel) ütlemise Virulane viljapunni, harjakas aganepunni Viru mees viljapulli, Harju mees aganapulli, rannamees rabakalitsa. See sisaldab eneseupitamist teiste arvel vastandamise kaudu - jõukad põllumehed, vaesed kalamehed. Ka kõnekäändudes leidub sedalaadi iroonilist võrdlevat osatamist.

Kerge elu nagu rannamehe sulasel - mutku istu ja sõua, sõisa ja via. (Jõh) Maamees helpigu pudi, asi nudi. (Rak)

Mees kui merihärg, rind kui sääse turi, reied kui pitskid, nina pikk kui Nissi kiriku torn. (Kad)

Nagu rannamehe pulmas. [Näiliselt rikkalik.] (Kad)

Ühes nõus nagu rannamehe härjad. (Hlj, Kuu)

Naabripilgete eriliigina tulevad kõne alla keelepilked, st mõne murdekeele eripära tögamine. Virumaa puhul on selleks õ-hääliku ületarvitus ning teatav vanapärasus Alutaguse murde alale jäävate kihelkondade (Jõh, lis, Lüg) elanike kõnepruugis. Ehk nagu pilgatavad ise on nentinud, kui meie murrakut taheti osatada, siis ütles mõni nii: “Õrav istus õksa pääl ja õksendas” (Jõh). Nagu näidetest näha, kõlasid seesugused osatamised üsna ühtemoodi:

Eile õli, et õksendas, täna õstaks, aga ei õle. (Lüg)

Õle uhke, õle, küll tuleb sinul ka õinapäev! Õrav õli õkaspuu õtsas, õgis ôkkaid ja õksendas. (Iis)

Murdepilgete kõrval moodustavad aga põhilise osa naabrite pihta suunatust siiski sõimufolkloorina tuntud nimetamised. Viru vares on laiemalt tuntud virumaalaste kohta käiv pilge, mille on ära märkinud oma sõnaraamatus 1869. aastal juba Ferdinand Johann Wiedemann (tähenduseks 'kohmaka inimese kohta'). Kirjapanek pole üllatav, sest juba regilauludest leiab seesuguse osatava nimetamise: Oi teie viru vareksed, aru andunud arakad. Ärge sööge mu südanta, ärge jooge mu jumeta. Sööge soosta sambelaida (laul “Ärge sööge mu südant”). Kõnekäändudes on seda pejoratiivi kasutatud erisuguste väljendite koosseisus.

Alt ära, harjukad, viru varesed tulevad! [Kui noored mehed ja poisid ütlevad vahest; see sõna on vist Virumaalt tulnud.] (Jüri)

Kisendab nagu viru vares (Saarde)

Oh sa vana Viru vares oma jutuga! [Kui mõni kaunis naljakaid juttusid puhub, mis päältkuulajaid naerma paneb.] (Halliste)

Seal oli inimeisi ku Viru varesid (Põltsamaa); jusku Viru varesi kokku 
juusnud (Häädemeeste); inimesi lahti lastud kui Viru vareseid (Laiuse); neid tuleb nagu Viru vareseid (VMr); siin om neid kui Viru varessit - üts ei kuule, tõne ei näe, kolmas viil kogundi sõke (Helme).

See aed on nagu varblastel või viru varestel tehtud, lendab aia pääle ja aed vajub kohe kokku. [Aed, mida on halvaste ja viletsaste tehtud, mis ei ole seisev ega vastupidav, selle kohta üteldakse] (Saarde).

Sõna viru/virulane kasutati aga muudegi negatiivse varjundiga ütlemiste koosseisus. Näiteks kui keegi liialt peale käis millegi vastumeelsega, tavatseti öelda: Vii Virule, vii turule, situta siakünale, aga mitte minule! (Kuusalu). Samuti esitati seda ühe kindla paikkonna nime eufemistlike nimetuste osana mõnede looma- ja taimeriigi mitte kõige meeldivamate esindajate kohta, kõrvutades neid sel moel ühe kindla piirkonna elanikega: virulane 'herilane', viru pulk rakvere raibe 'kollaste õitega (ristõieline) umbrohi, kasvab suviviljas'.

Siinkohal tasub ära märkida sedagi, et soomlased olevat virulasi kutsunud suisa viru kuraditeks, nimetus, mis on leidnud koha ka vene keeles (estonskije kuraatõ) (Remmel 2003: 161). See seletaks osaliselt ka alliteratiivset ühendi viru veri tausta, mis osutab justkui teatavale väljavalitusele - tunnustussõna julgustüki sooritanud või kartmatu mehe kohta. Kõnekäänulistes väljendites esineb seesugune fraas küll pigem irooniana:

Viru veri ei värise! (Sim, Kuusalu); Viru veri ei värise ja taku särk ei kärise (Tallinn); Viru veri ei värise, Kadrina kaigas ei sammelda (Kad) Viru veri ei värise, Petseri puss ei roosteta, Kadrina kaigas ei sammelda $(\mathrm{VNg})$

Kui viru vares käibis omamoodi üldnimetusena kogu Virumaa elanike kohta, siis leidus ka nimetusi, millega peeti silmas ühe kindla piirkonna või küla inimesi. Nii tavatseti Porkuni inimesi nimetada Porkuni põrssavarasteks. Räägiti suisa põrssavarga vallast ja Porkuni põrsavaraste kualist. Sama nimetust on kasutatud koos ümbruskonna teiste külade elanike pihta käivate pilkenimedega:

Porkuni põrsavaras, Kiltsi kitsevaras (Sim)

Saksi soojaleiva nolbesed, Porkuni põrssavargad, Kalle mussid, Moe rotid $(\mathrm{Kad})$

Ka on just Virumaalt, täpsemalt Haljalast, kirja pandud rohkelt teistegi külade elanike sõimunimetusi:

Külapoisid sõimasid üksteist külanimede järgi: "Vihula varesed (ka plaksnokad), Annikvere harakad, Metsiku mesilased, Kavastu kajakad, Villandi viletsad, Sagadi sahklusikad." (Hlj, Kad)

Suru suur soolatera, Läsna raske raudlähker! (Hlj) 
Tudu elanike kohta leiab väljendi Matt tuhka ja kaks tudulast! Sellise ütluse tekkepõhjused peituvad omaaegses vahetuskaubanduses, nagu selgub Iisakust kirja pandud selgitusest:

Sajandi esimesel poolel vedasid Tudu mõisa moonakad Kunda tsemenditehasest Tudu klaasivabrikule tuhka, mis oli vaja klaasi valmistamiseks. Tuha eest pidi aga Tudu mõis andma tsemenditehasele vastutasuks tööjõudu (töölisi) vastavalt ära veetud tuha kogusele. Sellest siis Roela meeste pilkelause.

Oma osa said aga ka Roela mehed ise, kelle kohta on mitmeid tögavaid ütlemisi, sh nimetus Roela ratasninad (VJg), mille pejoratiivsus seisneb omaaegse eufemistliku sea-nimetuse kasutamises.

Omaga väljas kui Roela mees lehma põhuga: põhk otsas, lehm otsas. (VJg) Läheme Roela Nirgi Tõnu linatalgule lapule. [Mardipäevaks pidid olema kõik välistööd lõpetatud, ka linatalgud. Kõige viimased olnud alati Roelas Nirgi Tõnul just mardipäeval.] (VJg)

Läheb nagu lähkritöö Roela mehe käes. (VJg)

Nagu kõigist neist nimetamistest nähtub, on siingi kesksel kohal algriim, mis annab vormilise aluse taoliste väljendite kujunemisele.

Seesuguse meie-nemad vastandamise kokkuvõtteks sobib ütlus, mis on samuti pandud kirja Virumaalt: Oleks ta veel niisuke nagu mina, aga ta on veel hullem kui sina!

Virumaa puhul torkab silma veel mõnede kohanimede - Rakvere ja Narva kasutamine pilkamise eesmärgil. Põhjuseks on tõenäoliselt nende kui omaaegsete Venemaa kubermangude kreisilinnade staatus (nii tavatseti Rakvere linna kohta kasutada koguni nimetust Viru Peeterburg). Nii võidi nentida: Mina pole kaugemal käind kui Rakvere linnas ega kõrgemal kui lakas (Hlj). Leidub aga ka sama väljendi variant, milles linna nimi on asendatud ühe Viru-Jaagupi kihelkonna küla nimega: Ei mina ole elus kaugemale saand kui Tudusse ja kõrgemale kui lakka (Hlj).

Sääraseid tögavaid-naljatavaid ütlemisi on kirja pandud nii naabermaakondadest, st Harju- ja Järvamaalt, kui ka virumaalaste endi seast. Nii mõnedki ütlused on saanud laialdase tuntuse üle kogu Eestimaa. Näiteks väljend äkiline nagu Rakvere kohus. Küllalt vana (1890. aastatest) väljendi tagamaad on tänaseks küll unustusehõlma vajunud, ent ühe põhjendusena võib võtta ehk järgmist Põltsamaalt pärinevat: Et vanasti Rakveres kõige valjum kohtunik siin ümberkaudu on olnud, siis ööldakse mõnest inimesest nii, kes oma kurjuse poolest kaugele kuulus on (Põltsamaa). Omamoodi selgituse võib välja lugeda 
ka sõnamängulisest naljatamisest: Viru rand on sakiline, Rakvere kohus äkiline (Kadrina).

Rakvere nime leiab ka 1970. aastate Tartu koolilaste sõnavarast, kus tuntud kellaküsimise väljendit on täiendatud just mainitud linna nimega: Mis kell näitab? - Kell näitab Rakvere aiateibaid (rohkem on levinud väljend Mis kell näitab? - Aiateibaid.).

Terve rida väljendeid on Narva linna nimega. Siingi on tegemist peaasjalikult osatamistega, pikemate ütluste seast leiab ka vähem või rohkem negatiivse varjundiga nimetusi, näiteks sõimusõnana narvanägu ja kaupmeeste kohta narvanaised (VNg, VJg).

Nuga on nüri, istu selga ja sõida Narva. (Lüg, VNg)

Narvas narritakse hobune ära, aga mina ikke sü̈̈llane. [Kui kedagi alati süüdistatakse igas asjas.] (Iis)

Ninda vägev mies, et siinpuol Narva jõge ei õle tõist, kui viinapudel tühi, siis katsub, kust raha võlga saab. (Lüg)

Näe ilmatarka! Käis Narva turul ära, nü̈̈d tiab kõik, kuda kuskil maal elatasse! (Iis)

Ette tuleb ka teiste kohanimedega väljendeid, ent ühtlasi on olemas ka ütlused, milles paika ei määratleta. Nii võidi öelda: higistab nii kui kass vorstisarja kallal (Rak, VJg), aga ka: mures kui Purtse kõrtsi kass vorstisarja kallal, ei tea, mida võtta ehk mida jätta (VJg).

Rahvaluulele omaselt võidi ainest kohandada nn oludele sobivaks, näiteks teise piirkonna kohanime välja vahetades. Kui Kuusalust on kirja pandud Nagu vanapagan, et kuhu pääsen, kuhu jõuan: Kuusalus on kuued pulmad, Kahalas kaheksad lapsevarrud, siis Haljalast hoopiski seesugune ütlus: Purtses pulmad, Vaekülas varrud, Kalikülas kaks meest taplevad, kuhu ma vaene jõuan!, milles esinevad kolm küla Virumaa eri kihelkondadest: Purtse - Lüganusel, Vaeküla - Viru-Jaagupis, Kaliküla - Viru-Nigulas. Niisugune loominguline lähenemine on taas ilmekas kinnitus arusaamale, et paikkonnale omast tasub alati otsida ka rahvaluulest.

Kokkuvõtteks võib nentida, et Virumaa vanasõnade ja kõnekäändude näol on tegemist mitmekesise ja ainulaadse rahvaluulematerjaliga, mis eristab seda piirkonda teistest. Olgu selleks siis ajaloolised, geograafilised, sotsiaalsed või muud põhjused, on just sealkandis säilinud eripärast ja seda aastasadade tagant. Tähelepanuväärselt kohtab siin kirjapandud poeetilistes pärimustekstides kõrvuti regivärsivormi, võõrmõjusid ja laene, milles võib näha aga oskust säilitada oma ja sobitada sellega teistsugust. 


\section{Kommentaarid}

1 Artikli valmimist on toetanud Euroopa Liit Euroopa Regionaalarengu Fondi kaudu (Eesti-uuringute Tippkeskus), see on seotud Eesti Haridus- ja Teadusministeeriumi uurimisprojektidega IUT 22-5 ja EKKM14-385.

2 Paberväljaande kõrval on olemas ka elektrooniline variant Eesti vanasõnad, mis küll sisaldab üksnes vanasõnatüüpide tiiteltekste, mitte aga variante.

3 Varaseimad Virumaa päritolu paröömilised tekstid pärinevad juba märksa varasemast ajast. Nimelt Fr. R. Kreutzwaldi käsikirjalisest kogust aastast 1864. Samas on nende originaalsus pigem kaheldav ja määratletav kirjamehe omaloominguna (vt Krikmann 2006).

${ }^{4}$ Seda kinnitab ka artiklis esitatud vanasõnade leksika analüüs. 100 enimesinenud sõna seas on järgmised nimisõnad (langevas järjestuses kümme sagedasemat): naine, mees, päev, töö, leib, jalg, inimene, raha, jumal, poiss.

${ }_{5}^{5}$ Nurksulgudes on toodud kõnekäänu tähenduse selgitus arhiivitekstides.

\section{Allikad}

EKFA = Eesti kõnekäändude ja fraseologismide andmebaas. Tartu: Eesti Kirjandusmuuseumi folkloristika osakond (http://www.folklore.ee/justkui/ - 20.07.2016).

Eesti regilaulude andmebaas. Tartu: Eesti Kirjandusmuuseumi Eesti Rahvaluule Arhiiv (http://www.folklore.ee/regilaul/ - 20.07.2016).

EV = Hussar, Anne \& Krikmann, Arvo \& Normann, Erna \& Pino, Veera \& Sarv, Ingrid \& Saukas, Rein (koost), Krikmann, Arvo \& Sarv, Ingrid (toim) 1980-1988. Eesti vanasõnad. Monumenta Estoniae Antiquae I-V. Tallinn: Eesti Raamat.

Vanasõnad. Tartu: Eesti Kirjandusmuuseumi folkloristika osakond (http://www.folklore. ee/rl/date/robotid/leht1.html - 20.07.2016).

\section{Kirjandus}

Hussar, Anne 2013. Ida-Virumaa vanasõnadest. Rüütel, Ingrid (koost ja toim). IdaVirumaa rahvakultuurist. Teine, parandatud ja täiendatud trükk. Rakvere-Tartu: Viru Instituut, lk 93-107.

Krikmann, Arvo 1981. Meri andab, meri ottab. Valimik Lahemaa vanasõnu. Tallinn: Valgus.

Krikmann, Arvo 1997. Sissejuhatus folkloori lühivormidesse: Põhimõisteid, žanrisuhteid, üldprobleeme. Tartu: Tartu Ülikooli Kirjastus.

Krikmann, Arvo 2006. Tekstide päritolust ja rahvaehtsusest Kreutzwaldi vanasõnade ja kõnekäändude käsikirjas. Ettekanne Akadeemilise Rahvaluule Seltsi kõnekoosolekul 22. veebruaril 2006 (http://www.academia.edu/4630122/Tekstide_p\%C3\%A4ritolust_ja_ 
rahvaehtsusest_Kreutzwaldi_vanas\%C3\%B5nade_ja_k\%C3\%B5nek\%C3\%A4\%C3\%A4 ndude_k\%C3\%A4sikirjas - 20.07.2016).

Must, Mari 2000. Vene laensõnad Eesti murretes. Tallinn: Eesti Keele Sihtasutus.

Mälk, Vaina 1976. Vadja vanasõnad eesti, soome, karjala ja vene vastetega. Tallinn: Eesti Raamat.

Pajusalu, Karl \& Hennoste, Tiit \& Niit, Ellen \& Päll, Peeter \& Viikberg, Jüri 2002. Eesti murded ja kohanimed. Tallinn: Eesti Keele Sihtasutus.

Remmel, Mari-Ann 2003. Viru mees viljapulli, Harju mees aganapulli. Piirkondlike suhete kajastumisest eesti rahvapärimuses. Mäetagused 21, lk 141-192 (doi: 10.7592/ MT2002.21.remmel).

Anneli Baran - Eesti Kirjandusmuuseumi folkloristika osakonna vanemteadur. anneli@folklore.ee

\section{Summary}

\section{Proverbs and sayings of Virumaa}

\section{Anneli Baran}

Keywords: dialectism, phraseological expressions, place name, proverbs, runic verse

The article tackles short forms of folklore in one of Estonian regions - Virumaa. The discussion maps the close ties that exist between old parishes in terms of folk material, characterised by archaic and dialectal traits as well as by a strong influence from the traditional folk songs in runo verse (regilaul). Another regional characteristic is the influence of kindred peoples who once lived in the same area as well as from neighbouring peoples. The proverbs and sayings display a richness of unique expressions but also the first mentions of well-known Estonian traditional expressions. Next to folk sayings, humour related to neighbours as well as pejorative sayings based on place names are also discussed, with a specific focus on regional characteristics.

Anneli Baran is Senior Research Fellow at the Department of Folkloristics of the Estonian Literary Museum.

anneli@folklore.ee 